NBER WORKING PAPER SERIES

\title{
COSTS AND BENEFITS OF PRENATAL SCREENING FOR CYSTIC FIBROSIS
}

Joseph P. Fenerty

Alan M. Garber

Working Paper No. 2749

NATIONAL BUREAU OF ECONOMIC RESEARCH

1050 Massachusetts Avenue

Cambridge, MA 02138

October 1988

This research was carried out as part of NBER's project in Health Economics. Any opinions expressed are those of the authors not those of the National Bureau of Economic Research. 
NBER Working Paper \#2749

Jctober 1988

\section{COSTS AND BENEFITS OF PRENATAL SCREENING}

FOR CYSTIC FIBROSIS

\section{ABSTRACT}

Newly-developed genetic tests based on restriction fragment length polymorphisms (RFLPS) promise to facilitate the early detection of genetic diseases. Several such tests are now available for the prenatal detection of cystic fibrosis (CF), a common and costiy disease. The tests for CF are currently 1 imited to prenatal diagnosis in siblings of a victim of CF. Direct gene probe tests, which have yet to be developed for CF, would be applicable even in families that have not already borne a child with the disease. We examine the costs and benefits of prenatal testing for cystic fibrosis using existing RFLP-based tests and using a hypothetical direct gene probe test. We find that even an expensive RFLPbased testing program produces substantial net benefits, because it is applied in pregnancies in which the risk of CF is $25 \%$. If a direct gene probe test is applied in all pregnancies, it will need to be much less expensive to generate net benefits, and it will lead to the abortion of many normal fetuses unless it is highly specific. Because these new tests are likely to generate substantial savings in medical expenditures and to increase lifetime earnings, parents of CF-affected children may be subjected to strong pressures to participate in prenatal testing programs and to abort fetuses that test positive. It is imperative that the ethical dilemmas arising from this promising screening test be discussed openly before it becomes widely available.

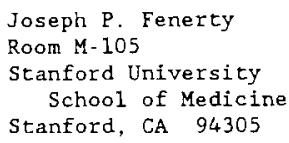

\author{
Alan M. Garber \\ NBER \\ 204 Junipero Serra Boulevard \\ Stanford, CA 94305
}




\section{INTRODUCTION}

Affected individuals, their families, and society as a whole share the burden of genetic diseases. Many victims of these diseases die during infancy. Others face a lifetime of intensive medical treatment, frequent hospitalization, and severe activity restrictions. The monetary cost to the patient's family and to society can be staggering. Less easily quantified but also important is the psychological toll; children who have genetic diseases often suffer impaired psychosocial development and their parents have high divorce rates. ${ }^{1,2,3}$ Few of the more than 3000 known human genetic diseases can be prevented or cured. ${ }^{4}$ However, recent advances in molecular biology have led to the development of prenatal tests that can detect these diseases, even when their precise etiologies and specific genetic defects are unknown. The new tests, based upon restriction fragment length polymorphisms (RFLPs), promise to determine with near perfect accuracy whether the fetus is afflicted with a genetic disease.

Such tests are now available for the prenatal diagnosis of one of the most devastating of all genetic diseases, cystic fibrosis (CF). This autosomal recessive disease, which affects the sweat glands, pancreas, lungs, and other organs, is incurable and costly. 5.0 Pulmonary exacerbations can cost more than $\$ 18,000$ if treated in the hospital, and 01 der children may have these episodes several times in a year. ${ }^{7}$ While extensive supportive care has prolonged the survival of CF patients, most die by their mid-twenties. CF is the most common of all lethal genetic diseases among caucasians in this country, with an incidence of about 1 in 2,000 births. ${ }^{8,9,10,11}$ The $25 \%$ risk of CF in subsequent pregnancies deters many parents of children with CF from bearing more children. ${ }^{12}$ Because many of these couples are eager to reduce this risk of $C F$ and give birth to unaffected children, $C F$ is a prime target for genetic testing. At one CF center $92 \%$ of the still-fertile parents with CF-affected children expressed interest in prenatal diagnosis and more than $70 \%$ claimed that they would 
have more children if an accurate prenatal test were avajlable. ${ }^{13}$

We report here the results of an analysis of the costs and benefits of prenatal genetic testing for cystic fibrosis. Our analysis is limited to the monetary consequences of CF -the direct health care costs of the disease and the effects of lost income due to death and disability. The analysis of this test differs from many cost-benefit analyses of health care because the disease is incurable and can only be prevented by averting the birth of affected children. The financial impact of the test depends on choices made by parents who discover that their fetus is affected. If they chocse to have more children, carrying to term only those fetuses who test negative, population-wide earnings will rise more than if they terminate or avoid subsequent pregnancies.

We also evaluate the consequences of testing with a direct gene probe test. Such tests are less cumbersome and may replace RFLP testing. Although direct gene probe tests for CF are not currently available, they could be oroduced soon after the CF gene is identified and sequenced, a breakthrough that many experts believe is imminent. ${ }^{14,15}$ Unlike RFLPs, which can only be used when there is a family history of the disease, direct gene probes will allow detection of the disease gene in members of the general population, whose risk of bearing a child with CF is about 1/500th as great. Universal application of a highly accurate probe. if fetuses who tested positive were aborted, would also prevent nearly all births of CF. affected children.

\section{THE NEW GENETIC TESTS}

Genetic tests for the prenatal detection of CF employ restriction fragment length polymorphisms of the DNA sequences near the CF gene to track disease inheritance in families. ${ }^{16}$ Similar tests have been developed for the detection of sickle cell anemia, polycystic kidney disease, Huntington's disease, and Duchenne's muscular dystrophy. $17,18,19.27$ These tests allow families to determine the disease status of a fetus (affected, unaffected, or heterozygous carrier) as early as the ninth week of pregnancy. Because RFLP testing 
requires genetic information from family members to determine whether the fetus has the disease, samples must be obtained from each parent, an affected sibling (or other affected relative), and from the fetus at risk. These requirements usually make it impossible to apply RFLP testing to avert the birth of the first CF-affected child in a family.

RFLP testing uses the individual's pattern of DNA fragments as a marker for the presence or absence of the CF gene. It places these patterns in the context of the known disease states of the family members; thus, an exact match of RFLPs from the affected relative and the fetus indicates that the fetus is probably affected as well. To increase the probability that the test will be able to discriminate between the parental chromosomes and determine which chromosomes carry the disease gene, the genetic probes and enzymes used in RFLP testing are chosen to be highly polymorphic in the testing population. The ability to distinguish the parental chromosomes is called informativeness. An uninformative test, because it does not indicate whether the fetus inherited a pair of the disease-carrying chromosomes, does not influence the probability that the fetus has the disease.

The tightness of the linkage between the markers and the $C F$ gene locus also affects the performance of the test. For example, in a given family the test may be informative for two markers that appear on both sides of the CF gene. These flanking markers make it possible to detect whether recombination has occurred between the CF gene and the test probe binding site. Similarly, nearness of the markers to the CF gene reduces the probability of recombination and strengthens the association between the marker and the gene. Commercial laboratories claim to have accurate and informative tests because they use multiple flanking markers; for example, Collaborative Research of Waltham, Massachusetts, uses twelve probes which flank, and are at varying distances from, the cf locus. ${ }^{21}$

The RFLP-based prenatal tests for CF appear to be substantially more accurate than the alternative, enzyme assays, which are neither sensitive nor specific. ${ }^{22,23}$ Despite the great promise of the new tests, they have significant drawbacks: they are expensive and they can predict disease status incorrectly. In routine use, errors that occur in laboratory 
processing, such as mislabeling specimens, might occur. Secondly, if recombination occurs, the RFLP patterns might no longer be linked to the disease gene. Because the rate of recombination is roughly proportional to the distance between the marker and the disease gene, and because most laboratories use markers that are near the disease gene, such recombination is unlikely for most of the available tests. Third, the mutation causing $C F$ might not be at the same locus in all persons, al though this is unlikely. ${ }^{24}$ failure to obtain fetal tissue would preclude testing, but ongoing improvements in chorionic villus sampling and amniocentesis are likely to diminish both the failure rate and the incidence of maternal and fetal complications. ${ }^{25}$ It is also possible that a test will be noninformative in a particular family, but most labs now claim that their tests are informative in at least $97 \%$ of the families tested.

Incorrect or equivocal test results $c$ an have fateful consequences. Fal se positive tests lead to the abortion of unaffected fetuses, while false negatives lead to the birth of affected children. The frequency of these errors is unknown. No published studies have reported the sensitivity and specificity of RFLP tests in human populations. Preliminary results of testing $\mathrm{CF}$-affected children and their siblings suggests that the tests are extremely accurate (personal communication, H. Kazazian, Johns Hopkins University), and it is assumed that over $99 \%$ of test results are correct. ${ }^{26,27}$ However, whether these excellent results will be duplicated when the tests are used on a wider scale is unknown.

For each 1,000 pregnancies tested with a test that is $99 \%$ sensitive and specific, 745 of the fetuses will test negative, of which two would be affected; 255 fetuses test positive, of which seven would be unaffected. Thus, nine of every 1,000 tested fetuses will be misdiagnosed, two of which will have CF. Because the genetic tests are the only technology that can reliably determine whether a fetus had CF, it would be difficult to verify the false-positive rates of these tests. Eventually, however, the false-negative fetuses that are carried to term will be recognized as misdiagnoses. 


\section{METHODS}

\section{POPULATIONS}

Prenatal testing for CF based on RFLPs can only be applied in families of CF-affected individuals. In this population, the probability that each pregnancy will yield a CF-affected infant (the pre-test risk) is $\mathbf{0 . 2 5}$. We assume that only women who would consider abortion will undergo testing. Since the Cystic Fibrosis Foundation currently has over 15,000 patients in its registry, thousands of American families are candidates for testing. For the analysis of a hypothetical direct gene probe test applied to the general population, we assume that one in twenty caucasians is a heterozygous carrier of the CF gene, so that one of every 1,600 pregnancies will be affected. ${ }^{6}$

\section{COSTS of CF}

Table 1 presents some published estimates of the medical expenditures for $\mathrm{CF}$; although the estimates vary widely, it is clear that the amounts involved are many thousands of dollars per patient per year. The extraordinary costs of caring for CF patients arise from frequent hospitalizations and the need for expensive medications, such as antibiotics and replacement pancreatic enzymes. We assume a constant expense of $\$ 8000$ per year for CF-related health care. We use 25 years as our estimate of the mean life expectancy, based on the most recent (1985) reports of the Cystic Fibrosis Foundation. ${ }^{28}$ Annual costs of care, and all costs and earnings in future years, are discounted at $5 \%$. These figures are conservative estimates of the total costs of care of cystic fibrosis, since both life expectancy and the cost of the therapy have been increasing.

In cost of illness or cost-benefit studies, costs are usually divided into two categories, direct and indirect. ${ }^{29,30} \mathrm{~A}$ comparison is always implicit in the cost estimates; usually the comparison is to the expenditures and earnings that would accrue if the disease could be eradicated costlessly. The direct costs of cystic fibrosis include those of testing, abortion or birth, health care, and all costs associated with preventing or treating 
the $i l$ lness. Indirect costs are the earnings lost due to disease-related disability and early death. When compared to unaffected individuals, CF patients have brief lives, frequent work absences (if they survive to working age and enter the labor force), and low (often negligible) expected earnings. We define the change in indirect costs, or the earnings

benefit of testing, as the difference between the expected value of (discounted) lifetime earnings under a testing strategy and under a no testing strategy. Lifetime earnings under a testing strategy depend on additional decisions made by the parents. For example, if a fetus tests positive, the family opts for abortion, and they proceed to bear a normal child in a subsequent tested pregnancy ("replacement" of affected and aborted fetuses), the change in indirect costs is the difference between the lifetime earnings of a norma child and the lifetime earnings of an affected child. If they opt to abort and do not have another child ("no replacement"), the earnings benefit of testing will be the difference between the earnings of an abortus and the discounted future earnings of an affected fetus. Pain, suffering, and other non-monetary impacts of the disease are not included:

To compare the lifetime costs (direct and indirect) for affected and unaffected children, it is necessary to account for the total lifetime health care costs of unaffected individuals as well: as the decreased earnings of individuals with CF. Therefore, the net present value of an unaffected individual's lifetime health care costs is subtracted from his or her expected lifetime earnings to get the incremental difference in total costs (both indirect and direct) between unaffected and affected individuals. We estimated average Tifetime health care costs for the general population by using age-specific annual health expenditures from the Consumer Expenditure Survey, ${ }^{31}$ age-specific mortality rates from U.S. Tife tables, ${ }^{32}$ and an inflation-adjusted rate of discount of 5\%. These figures imply that the average discounted value of iffetime health expenditures at birth is S11,163: This figure appears in Table 2, as do all the dollar amounts used as central estimates of the costs and benefits in our analysis. These cost estimates are from the providers of the tests themselves, local hospitat charges, insurance reimbursements, and published reports. Although 
the total If fetime health care expenditures of unaffected individuals are large, most of them occur in the later years of life. These delayed costs add little to the present value, or discounted lifetime costs of care, since even large costs add little to the present value if they are delayed for many years and discounted at a $5 \%$ annual rate.

\section{COSTS OF TESTING}

Prenatal RFLP testing requires tissue from the mother, father, affected relative, and the fetus at risk. Peripheral blood provides the DNA for all the family members but the fetus, and the cost of venipuncture is assumed to be negligible. Costs for testing the tissue vary: Collaborative Research currently charges $\$ 1,100$ to test the family ( $\$ 800$ for the family members and $\$ 300$ for the fetus); Baylor University charges $\$ 600 /$ family (or $\$ 150 /$ sample); and Integrated Genetics of Framingham, Massachusetts charges $\$ 850 /$ family. (A) though we have used data from Collaborative Research as the basis of our analysis, this does not imply our endorsement of this or any other specific assay.)

There are two methods of obtaining fetal tissue for testing. The test in most common use is amniocentesis, which can be performed beginning at about the sixteenth week of pregnancy. Chorionic villus sampling (CVS) is a newer procedure that can be performed as early as the ninth or tenth week of pregnancy. ${ }^{33}$ The base-case analysis assumes that CVS wiil be used, because many families undergoing prenatal genetic testing are likely to prefer the earlier diagnosis it provides. In addition to these costs, a slight risk of miscarriage is associated with each of these procedures. Aside from the risks of venipuncture itself, no further risks result from obtaining tissue from family members.

\section{TEST CHARACTERISTICS}

Some laboratories that perform these tests, such as Collaborative Research, do not report the results of the test as "positive" or "negative." Instead, they report the probability that the fetus will have CF. Although the test performance and the operating 
characteristics have not been studied prospectively, we assume that the test is extremely accurate, as the laboratories claim, and for the purposes of our calculations; we estimate both the sensitivity and specificity to be 0.99 . We then show how the results of our analysis change as we modify these assumptions about test performance.

\section{INCORPORATING COSTS AND PROBABILITIES INTO A DECISION FRAMEWORK}

Our analysis explores the consequences of two major decisions: whether to test and whether to abort. A family that decides to abort a fetus testing positive faces a third decision: whether to "replace" the aborted fetus with another pregnancy. The outcomes, their values, and the probabilities of various events are schematized in the decision tree that appears in Figure 1. ${ }^{34}$ The upper two-thirds of the tree shows the costs and outcomes based upon a decision to test; the lower one-third is based on a decision not to test. Following conventional notation, this decision tree represents "decision nodes, "or points at which actions must be taken by the decision maker, as boxes. Circles represent "chance nodes," or points where the outcome is uncertain. The figures adjacent to the chance nodes are the probabilities of each of the outcomes. We explore the decision problem from the perspective of a policymaker (e.g., an insurer or Medicaid official deciding whether to offer or require these tests). The policymaker weighs the relative costs of the options and the values of the possible outcomes. The corisiderations for a woman (or family) who has had a child with CF are displayed in Figure 1. First, note that the pre-test probability of CF is 0.25 . If the test is $99 \%$ sensitive and specific, a positive test result will be obtained 25.5 percent of the time and a negative test result 74.5 percent of the time. The post-test probability of disease, given a positive test result, is 0.97 , and the probability of disease with a negative test result is 0.003 .

The costs and outcome probabilities associated with the decisions on Figure 1 are based on the central estimates (Table 2) and the following assumptions: 1) fetuses testing positive are aborted; 2) under the replacement condition, the families attempt to conceive, testing 
subsequent fetuses and aborting those that test positive, until they conceive a fetus that tests negative; 3 ) under the no replacement condition, the families do not attempt further pregnancies if the fetus tests positive and is aborted; 4) fetuses testing negative are carried to term; and 5) families that refuse the test carry pregnancies to term. The dollar amounts on the right side of the tree are the sums of the costs and benefits for each of the associated outcomes. The expected value of each branch is the product of its probability and the costs incurred in reaching that branch (testing, abortion, live birth, and CF health care summed as direct costs, and lost earnings and disability added as indirect costs); thus, one can work back to estimate average vaiues for the decisions preceding the terminal branches. This results in the numbers under the words Iest and № Test; these numbers can be used to compare the expected values of testing and not testing.

A separate analysis was performed on hypothetical data for a direct gene probe that could be applied to all pregnant women (see Appendix). The central assumption is that the test would cost $\$ 10$. Because $C F$ can only be inherited if both parents are carriers, we assume that the least expensive way to perform such pregnancy screening would be to test only one member of a couple, then test the spouses of those who test positive (sequential strategy). An alternative approach, testing all fetuses, would require performing amniocentes is or cVS for every pregnancy, and would be prohibitively expensive unless these procedures were being performed for other reasons. We further assume that the sensitivity and specificity of the probe would be $99 \%$. Using these assumptions, we calculate the potential costs and benefits of such testing, and show how the estimated benefits vary as we alter the assumptions about the costs of the hypothetical probe, the test accuracy, and other uncertain quantities. 


\section{RESULTS}

\section{NET BENEFITS OF TESTING}

RFLP-based testing. Figure 1 illustrates, in the form of a decision tree, the consequences of testing. The cost figures are in 1985 dollars, and are estimated on a per fetus basis. Negative values are negative costs or, equivalently, positive benefits. The expected value of both the direct and indirect costs of testing are largest with "replacement" of all fetuses aborted after a positive test. Since the desire to give birth to unaffected children is: the primary reason for testing, individuals who choose testing would be expected to pursue the replacement strategy. The calculations for the replacement strategy are based on a maximum of four cycles of testing and attempted conception; because $25.5 \%$ of fetuses test positive in any round of testing, fewer than half of $1 \%$ of the families will need to go through more than four rounds of testing before conceiving a fetus that tests negative. Values for the total costs of testing with replacement appear as the upper of each pair of dollar values on Figure 1 (values without reptacement are in parentheses below). The expected benefit of testing is more than $\$ 145,000$, compared to aborting the pregnancy. Compared to abortion, giving birth to a child without prenatal testing produces a financial benefit of over $\$ 109,000$. Even in this high risk population three-fourths of the children will be unaffected and have normal lifetime earnings. The impact of testing, then, is the difference between these expected values, or about $\$ 35,000$ per pregnancy. Compared to giving birth at each pregnancy, a family that chooses testing with a replacement strategy generates greater benefits primarily because nearly all births are free of the curtailed earnings and excess health costs of CF.

The benefits of testing are smaller -: about $\$ 25,000$ per fetus - if the family does not opt for replacement. This figure represents a $25 \%$ reduction in the cost of CF care. Part of this reduced cost comes from the decreased number of live births for tested pregnancies (all untested pregnancies go to term), but birth costs are a small fraction of the total health care costs for CF-affected fetuses. The $\$ 10,000$ difference between the two strategies 
is the tradeoff between increased earnings of unaffected fetuses born if families replace pregnancies until testing is negative and the increased costs of repeated cycles of testing. Consequentiy, testing is economically preferred over not testing and replacement over no replacement.

If only the direct costs are considered, the least costly option would be to abort all fetuses so that no birth, testing, or health care expenses would be incurred. The fear of dauntingly high direct costs led many families to use contraceptives or to abort all pregnancies prior to the advent of prenatal testing. However, this strategy has high indirect costs, since the lost lifetime earnings of the unaffected individuals (estimated to be $\$ 198,000$ per fetus) far outweigh the expenses of birth and health care. If only earnings or indirect costs are considered, one would choose not to test because testing may lead to the abortion and loss of earnings of some unaffected fetuses. When both types of costs are considered, testing reduces direct costs while keeping earnings high.

Population-wide carrier screening. Under the central assumptions, the net benefits of population-wide screening with a hypothetical direct gene probe are small. The benefits depend on gene prevalence, costs of testing, and accuracy. At a relatively small level of error, population-wide screening will be unacceptable because many unaffected fetuses would be aborted. In addition, because the majority of CF patients are born to families that have no past history of the disease, compliance with testing programs will need to be extremely high in order to decrease the incidence of CF.

Assuming that the test has a sensitivity and specificity of .99 , and that the gene prevalence is 1 in 20, Figure 2 shows how the net benefit per couple tested varies with the cost of the test. A $\$ 10$ test would produce net financial benefits of $\$ 50$ per tested family; if the test cost slightiy more than 550 , it would generate net costs.

The prevalence of the CF gene alters both the efficacy of the test and the net benefit of testing. In the high risk population, very few errors in diagnosis will occur. In the general population, a screening test with the same sensitivity and specificity will result 
in more misdiagnoses. For example, the RFLP-based test in families with a prior history of CF results in misdiagnosis less than $1 \%$ of the time. In the general population, where the risk is approximately $0.06 \%$, there will be 29 falsely negative and 19 falsely.positive results per 1,000 tested fetuses, for an error rate of almost 5\%. (see the Appendix). Therefore, the successful application of prenatal genetic testing in high risk families with one or more CF-affected children does not imply that such a test will be useful in other populations.

\section{SENSITIVITY ANALYSIS}

The values of several parameters used to calculate the costs and benefits of prenatal screening for $C F$ are uncertain. We assessed the sensitivity of our findings to the assumptions about the values of key parameters, including the test characteristics (sensitivity and specificity), lifetime earnings, and the costs of testing, abortion, birth, and health care for both CF-affected and unaffected individuals.

RFLP-based testing. The net benefits of testing, assuming that parents attempt to conceive another child after aborting a fetus which tests positive (i.e., replacement), range from about $\$ 9,000$ if $C F$ does not generate any excess heal th expenditures, to over $\$ 35,000$ if CF care costs $\$ 8,000$ annually, to over $\$ 75,000$ if CF care costs $\$ 20,000$ annually. The net benefit of RFLP-based testing without replacement is about $\$ 12,000$ less than for the replacement strategy at any level of cost of CF care; the net benefit is positive under no replacement if CF care costs more than about $\$ 1,000$ annually.

As Figure 3 demonstrates, the net benefits of testing rise with the 7 ifetime earnings of an unaffected individual if the parents attempt replacement. Net benefits decline slightly with earnings under a policy of no replacement because falsely aborting a normal fetus becomes more costly as lifetime earnings rise.

A test that is frequently noninformative produces smaller benefits, on average, than a highly informative test. The diminution in benefits that results from noninformativeness 
depends on actions that the parents take when they confront a noninformative test. The net benefits are always greater if the parents opt against abortion in this situation, but even if they choose to abort when the test is noninformative, the test generates net benefits as long as it is informative about $85 \%$ of the time or more (Figure 4). Each of the commercial laboratories that we contacted claims that their test's informativeness substantially exceeds this value.

Although the benefits of using a screening test depend on the accuracy of the test, as reflected in the sensitivity and specificity, the benefits of CF testing change little with test accuracy in the range of relevant values. These tests are highly sensitive and specific, and the RFLP-based tests are applied in a high-prevalence population. As Figure 5 demonstrates, the net benefit of testing changes little as the test sensitivity or test specificity falls from 1 to .9 ; if the specificity is 1 , the net benefit of testing falls from about $\$ 38,000$ to $\$ 32,000$ as sensitivity declines from 1 to .9 ; the net benefit falls somewhat less if the specificity declines from 1 to .9. The purported sensitivity and specificity of all commercially available tests are substantially higher than the lower end of the ranges displayed here.

The net benefits of RFLP testing decline little as the cost of testing increases; even if it cost $\$ 5,000$ to test a family, the net benefits of testing would exceed $\$ 20,000$ with no replacement, and $\$ 30,000$ with replacement.

Carrier screening. In addition to the unknown cost of the hypothetical gene probe test, the sources of uncertainty in the estimates of the net benefits of carrier screening are the gene prevalence in the tested population and the accuracy of the test. Figure 6 shows how the net benefit per tested couple for CF screening varies with gene prevalence (assuming full compliance and a 510 test). In a population with a gene prevalence of 1 in $40(0.025)$, the benefits of screening are small. If the prevalence is 1 in 20 , the net benefit exceeds \$40 per couple. 
The test cost that is just high enough so that the benefits of a testing program equal the costs is called the threshold cost. At this cost, the decision maker will be indifferent between screening and not screening the population. Figure 7 shows the relation between the threshold cost of the screening and the gene prevalence. The benefits exceed the costs of testing as long as the test costs less than $\$ 100$, if the gene prevalence is 70 per 1,000 . If the prevalence is 40 per 1000 , the test produces net benefits only if it costs less than $\$ 40$.

As with the RFLP test, the accuracy of a carrier screening test will strongly influence the net benefit of a screening program. Figure 8 shows how the sensitivity and specificity affect those benefits. As in Figure 5, net benefits are positive for the expected accuracy for the test (sensitivity $99 \%$ and specificity $99 \%$ ). However, the benefit vanishes if both sensitivity and specificity are less than $95 \%$.

\section{DISCUSSION}

Although they have not undergone extensive clinical evaluation, RFLP-based tests appear to be highly sensitive and specific assays for genetic diseases. For many of the conditions that they detect, alternative tests are either inaccurate or unavailable.

Cystic fibrosis is perhaps the most promising candidate for prenatal screening because it is common, its treatment is costly, and it is ultimately fatal. Other genetic diseases, such as some forms of muscular dystrophy and lipid storage disorders, usually cause death early in infancy and do not result in several years of burdensome expenditures for health care. Some other genetic diseases, such as Huntington's disease, do not cause morbidity until late in the course of the disease, so that the excess medical expenditures attributable to the disease are small compared to the direct costs of CF. A large number of other fatal genetic diseases are exceedingly rare. The intense efforts to develop tests for CF are stimulated by its importance as a cause of suffering as well as by the scientific challenges it presents. 
Existing genetic tests for CF are limited to families that have already borne children with the disease. In this population, the $25 \%$ prevalence of disease means that the tests will misdiagnose very few fetuses. In the general population, CF occurs in only about one of 2,000 births. A screening test applied to all fetuses would need to be extremely specific to avoid the abortion of many unaffected fetuses. The costs of fetal testing, and the chances for error, could be reduced by first testing all pregnant women, then testing the spouses of those who test positive for the gene, and only testing fetuses after both parents test positive (see Appendix). Even this strategy would require a highly accurate assay. Furthermore, the cost of averting the birth of a child with CF would be high unless the screening test were inexpensive.

While RFLP-based tests usually cannot be applied until a family has borne a child with the disease, the families that use the tests can be confident that they will be able to bear unaffected children. If prenatal testing enables these families to have more children, of whom two-thirds will be CF carriers, the CF gene will become more prevalent among adults of childbearing age. Carrier screening may also increase the gene prevalence by increasing the number of childbearing heterozygotes. The prevalence of genes 1 inked to the CF gene would increase as well. The long-term consequences of the change in the genetic composition of the population are unknown.

\section{ETHICAL ISSUES}

Increased concern about the magnitude of health expenditures motivates the quest for opportunities to lower the costs of treating illnesses. The new tests for prenatal diagnosis of cystic fibrosis represent such an opportunity. The government programs and private insurance companies that pay for some of the costs of cystic fibrosis will have strong incentives to pressure parents of affected children to participate in screening programs and to abort affected fetuses. Even when the costs of testing exceed $\$ 1,000$, participation in such programs will generate large savings for insurers. While insurers and government 
programs might not compel families to submit to testing and to abort affected fetuses, they could deny reimbursement for health care of the "preventable" cases of CF. Because the disease can only be prevented by aborting affected individuals, many people will object to testing and its implications. Others will feel that the large savings that result from screening justify its widespread adoption, and that there is no social obligation to pay for the care of a disease that could have been prevented. It is likely that testing will be advantageous for insurers even in the absence of coercion, since a high percentage of the families at risk are likely to comply voluntarily. Nevertheless, in the absence of a consensus on these issues or of a procedure to balance the rights of families at risk against the costs to the larger population, it is imperative that these implications of screening be discussed and evaluated openly before testing becomes widely available.

A direct gene probe test presents somewhat different issues. It could sharply reduce the number of CF births because it could be applied to. all pregnant mothers, not just those who had given birth to an affected child. But because disease prevalence is low in the general population, prenatal testing of all fetuses would lead to the abortion of many unaffected fetuses. The sequential strategy described above, which tests the fetus only if both parents are found to be carriers, would sharply limit the number of false-positive tests while producing a small number of additional false-negative tests, compared to prenatal testing of all fetuses. Regardless of the strategy, any test applied to the general population would need to be relatively inexpensive to generate a net savings in health costs. Consequently, there is weaker pressure to test the general population than to test affected families.

Cystic fibrosis is one of many genetic diseases that will become targets for prenatal testing with novel molecular biology techniques. The strategies that result from prenatal diagnosis of such conditions need not be limited to abortion, but might include lifetime monitoring for signs of disease so that specific treatment could be instituted early. Some fear that a "brave new worid" of eugenics will be forged from genetic testing programs. 
Parents who seek the "perfect child" might abort fetuses with mild abnormalities or handicaps that could be detected by prenatal tests. Whether these fears will become reality depends on the responsible development and application of genetic tests. While the risk that any genetic test will be misused is real, it must be balanced against the substantial benefits that the new tests offer to families plagued by genetic disease. 


\section{APPENDIX: THE EFFECTIVENESS OF A SEQUENTIAL STRATEGY FOR POPULATION-WIDE SCREENING}

One parent is tested first. The second parent is tested only if the test shows that the first parent is a carrier of the $C F$ gene. If both parents test positive, the fetus undergoes testing for $\mathrm{CF}$.

Assuming that $1 / 20$ th of individuals of child-bearing age carry the CF gene, and that affected individuals are as likely to survive to birth as other fetuses, approximately one in 1,600 births will result in CF. In the following calculations we present rates per one million pregnancies; if no abortions are performed, 625 of these pregnancies will result in the birth of an infant with cystic fibrosis.

If the sensitivity and specificity of a direct gene probe test are each $99 \%$, the test yields the outcomes at each stage of testing as described in Figure 9 . The remainder of this appendix describes how the consequences of testing were assessed.

Stage I - - testing the first parent:

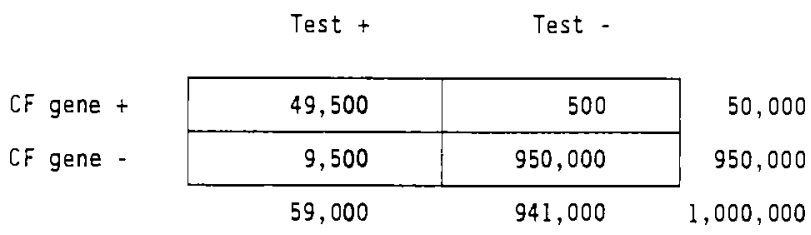

The $2 \times 2$ table above shows the results of testing in this population, classified by the true genetic status of the individuals. Of 1,000,000 parents tested, there will be only 500 false-negatives and 9,500 false-positive test results. A false-negative result leads to no further testing. One of every 80 false-negatives at the first stage will later result in the birth of an infant with $C F(1 / 20$ chance of pairing with another carrier, multiplied by $1 / 4$ chance that a child will have $C F$ when both parents are carriers). Consequentiy, the 500 false-negative test results at Stage I will result in the birth of approximately six 
children with CF. All positive test results lead to further testing (Stage II).

Stage II -- testing the second parent:

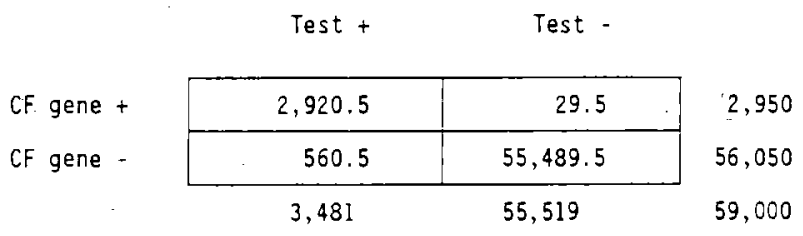

The 59,000 spouses of individuals testing positive in Stage I also undergo testing. Of these individuals, 2,950 will be carriers of the CF gene. Approximately 30 of the carriers will test negative. Since about $16 \%$ of the individuals testing positive in Stage I were false-positives, $21 \%$ of the false-negatives at Stage II (rather than 25\%) will result in the birth of children with CF. Consequently, false-negative tests at Stage II result in the birth of about 6 infants with CF.

Stage III - testing the fetus:

\begin{tabular}{|c|c|c|c|}
\hline & Test & Test. & \\
\hline $\mathrm{CF}+$ & 606.4 & 6.1 & 612.5 \\
\hline \multirow[t]{2}{*}{ CF - } & 28.7 & 2839.8 & 2868.5 \\
\hline & 635.1 & 2845.9 & 3481.0 \\
\hline
\end{tabular}

Stage III tests the 3,481 fetuses whose parents both tested positive. Because 560.5 of the Stage II tests are false-positives, and because about $16 \%$ of the true positives in Stage II are spouses of individuals who had a false-positive test result in stage I, only 2450.25 of the 3,481 fetuses tested are offspring of two carriers. Thus the prevalence of CF in the Stage III population is $17.6 \%$, rather than the $25 \%$ expected in the offspring of two carriers. 
This sequential strategy results in relatively few false-positives; despite the low prevalence of CF among all births, there will be only $29 \mathrm{fa}$ (se-positive tests in Stage III, meaning that the chances of aborting a normal fetus because of prenatal screening would be three in 100,000 pregnancies. There are six false-negative tests in Stage III; thus the number of unexpected births of affected infants is about 19 (slightly more than six births resulting from false-negatives in each stage of testing). Consequently, 1,062,481 genetic tests and 3,481 fetal tissue sampling procedures (amniocentesis or CVS) were done to detect 606 fetuses with CF, resulting in the abortion of 29 normal infants and missing 19 affected infants. If each test cost $\$ 10$, and amniocentesis or CVS cost $\$ 1,000$, the cost per case detected would be $\$ 23,260$. A less sensitive test would have a higher cost per case detected, while a less specific test might also be more costly because it would result in more Stage III testing. Furthermore, lower specificity would lead to the abortion of more fetuses who did not have CF. 


\section{REFERENCES}

1. Denning CR, Gluckson MM, Mohr I. Psychological and social aspects of cystic fibrosis. In: Mangos JA and Talamo RC, eds., Cystic Fibrosis: Projections into the Future. Stratton Intercontinental Medical Book Corp., New York, 1976: 127-51.

2. dewet $B$ and Cywes S. The psychosocial impact of cystic fibrosis. S Afr Med J $1984 ; 65: 526-30$.

3. Kollberg $H$. Sociomedical conditions of swedish patients with cystic fibrosis: a review of the past twelve years. Int $J$ Rehab Res 1982; 5:345-61.

4. McKusick, VA. Mendelian Inheritance in Man, 7th edition. Baltimore: Johns Hopkins University Press, 1986.

5. Andersen DH, Hodges RG. Celiac Syndrome. V. Genetics of cystic fibrosis of the pancreas with a consideration of etiology. Am J Dis Child 1946; 72: 62 .

6. Goodchild MC, Dodge JA. Cystic Fibrosis: Manual of Diagnos is and Management, 2nd ed: Philadelphia: Bailliere Tindall, 1985.

7. Donati MA, Guenette G, and Auerbach H. Prospective controlled study of home and hospital therapy of cystic fibrosis pulmonary disease. JPediatr 1987; 11l: 28-33.

8. Thompson MW. Genetics of cystic fibrosis. In Sturgess JM, ed.: Perspectives in Cystic Fibrosis: Proceedings of the 8th International Cystic Fibrosis Congress; Toronto, Canada. Toronto: Cystic Fibrosis Foundation, 1980: 281-90.

9. Romeo G. Cystic Fibrosis: a single locus disease. In Lawson D ed.: Cystic Fibrosis: Horizons. New York: John Wiley and Sons, 1984: 155-64.

10. Sturgess JM, Czegledy-Nagy E, Corey M, and Thompson MW. Cystic fibrosis in Ontario. Am J Med Genet 1985; 22 : 383-93.

11. Merritt $A D$, Hanna $B L$, Todd $C W$, and Myers $T L$. The incidence and mode of inheritance of cystic fibrosis. J Lab Clin Med 1962; 60: 998-1002.

12. Kaback M, Zippin D, Boyd P, Cantor R. Attitudes toward prenatal diagnosis of cystic fibrosis among parents of affected children; 15-28. In Cystic Fibrosis: Horizons. ed. Lawson D. John Wiley and Sons, New York, 1984.

13. Super M. Genetic counselling and antenatal diagnosis of cystic fibrosis. $J$ Royal Soc Med 1987; 80 (Suppl 15): 9-12.

14. Roberts L. The race for the cystic fibrosis gene. Science 1988; 240: 141-4. 15. Roberts L. Race for cystic fibrosis gene nears end. Science 1988; 240: $282-5$.

16. Farral1 M, Rodeck $C H$, Stanier $P$, Lissens $W$, Watson $E$, Law H-Y, Warren $R$, Super M, Scambler $P$, Wainwright $B$, Williamson R. First-trimester prenatal diagnosis of cystic fibrosis with linked DNA probes. Lancet 1986; 1 ; 1402-4. 
17. Chang $J C$ and Kan YW. A sensitive new prenatal test for sickle-cell anemia. New England Journal of Medicine 1982; 307: 30-2.

18. Reeders ST, Breuning MH, Davies KE, Nicholls RD, Jarman AP, Higgs DR, Pearson $\mathrm{PL}$, and Weatherall DJ. A highly polymorphic DNA marker linked to adult polycystic kidney disease on chromosome 16. Nature 1985; 317(6037): 542-4.

19. Hayden MT, Hewitt J, Kastelein JJP, Langlois S, Wilson RD, Fox S, Hilbert $C$, and Bloch M. First-trimester prenatal diagnosis for Huntington's Disease with DNA probes.

20. Old JM and Davies KE. Prenatal diagnosis of Duchenne muscular dystrophy by DNA analysis. J Med Genet 1986; 23(6): 556-9.

21. "Prenatal diagnosis of cystic fibrosis using DNA Probes (RFLPs)" Collaborative Research, Waltham, MA.

22. Boue A, Muller F, Nezel of C, Oury JF, Duchatel F, Dumez Y, Aubry MC, Boue 3. Prenatal diagnosis in 200 pregnancies with a 1 in 4 risk of cystic fibrosis. Human Genetics 1986; 74: 288-97.

23. Mulivor RA, Cook D, Muller F, Boue A, Gilbert F, Mennuti M, Pergament E, Potier M, Nadler $H$, Punnett $H$, Harris $H$. Analysis of fetal intestinal enzymes in amniotic fluid for the prenatal diagnosis of cystic fibrosis. Am J Hum Genet $1987 ; 40: 131-46$.

24. Klinger $K$, Stanislovitis $P$, Hoffman $N$, Watkins PC, Schwartz R, Doherty R, Scambler P, Farrall M, Williamson R, Wainwright B. Genetic homogeneity of cystic fibrosis. Nucleic Acids Research 1986; 14(21): 8681-86.

25. Hogge WA, Schonberg SA, Golbus MS. Chorionic villus sampling: experience of the first 1000 cases. Am J Obstet Gynecol 1986; 154(6): 1249-52.

26. Nugent CE, Gravius T, Green P, Larsen JW Jr, MacMillin MD, and Donis-Keller H. Prenatal diagnosis of cystic fibrosis by chorionic villus sampling using 12 polymorphic deoxyribonucleic acid markers. Obstet Gynecol 1988; 71: 213-5.

27. Super M, Ivinson A, Schwarz M, Giles L, Elles RG, Read AP, and Harris R. Clinical experience of prenatal diagnosis of cystic fibrosis by use of 1 inked DNA probes. Lancet $1987 ; 2(8562)$ : $782-4$.

28. Annual Report, Cystic Fibrosis Foundation, 1985.

29. Cooper BS and. Rice DP. The economic cost of illness revisited. Social Security Bulletin 1976; Apri1: 21-36.

30. Hartunian NS, Smart CN, and Thompson MS. The Incidence and Economic Costs of Major Health Impairments. Lexington, MA: Lexington 8ooks, 1981: 5-10.

31.31. U.S. Bureau of the Census, Statistical Abstract of the United States: 1988 (107th Edition). Washington, D.C.: U.S. Government Printing Office, 1987, Table 139, p.91. 
32. U.S. National Center for Health Statistics. Vital Statistics of the United States, 1985, Vol. II, Sec. 6, Life Tables. DHHS Pub. No. (PHS) 88-1104. Washington, D.C.: U.S. Government Printing Office, 1988.

33. Goidsmith MF. Trial appears to confirm safety of chorionic villus sampling procedure. JAMA 1988; 259: 3521-2.

34. Pauker SG, Kassirer JP. Decision Analysis. New England Journal of Medicine 1987; 316: 250-70.

35. Pauly MV. The economics of cystic fibrosis. In Lloyd-5till JD; Textbook of Cystic Fibrosis. Littleton, MA: John Wright, 1983; 465-76. 


\section{TABLE 1. ESTIMATED COSTS OF CYSTIC FIBROSIS}

Adjusted to 1985 Dollars

\section{Direct Costs}

\$ 18,640 National Heart, Lung, and Blood Institute estimate of annual medical costs $(1977)^{35}$

$\$ 12,444 \quad$ Median annual cost for the $51 \%$ of respondents who were hospitalized in the previous year, from a survey of adult patients $(1980)^{*}$

$\$ \quad 5,562$ Median annual cost for the unhospitalized $49 \%$ of patients - from the same survey (1980)

$\$ \quad$ Estimated mean annual expense for all patients $(1983)^{\star \star}$

$\$ 5,328$ Estimated mean annual prescription costs for the relatively healthy CF patient $(1985)^{\star *}$

* Results of the CF patient registry. CF Foundation, 1980

** Result of the patient survey, 1985. CF Foundation, Baltimore, MD. 
Table 2. Central Estimates for the Costs and Benefits of Prenatal RFLP Testing for Cystic Fibrosis

\section{(5\% discount rate)}

\section{Direct Costs}

Sampling fetal DNA

(chorionic villus sampling)

Testing fetal DNA

(Collaborative Research, Waltham, MA)

$\$$ 300

Sampling and testing family

(Collaborative Research)

$\$$

800

$\$$ 500

Abortion

$\$$

2,500

Birth

Present value of lifetime costs

of CF care ( $\$ 8,000$ for 25 years)

(see Table 1 above)

$\$ \quad 112,752$

Indirect Costs

(Lost Lifetime Earnings)

Present value of earnings lost if

an unaffected fetus is aborted 35

$\$ \quad 198,000$

Approximate present value of

earnings of a CF-affected fetus 35

$\$$

0

\section{Benefits}

Present Value of the lifetime earnings of a normal child $(\$ 198,000)$ less the present value of the medical care costs of an unaffected child $(\$ 11,163)$ if an affected fetus is replaced with an unaffected one $31,32,35$ 
Figure 1. Decision Tree for the Prenatal Diagnosis of Cystic Fibrosis, with Associated Costs

(1985 dollars)

with replacement (no replacement)

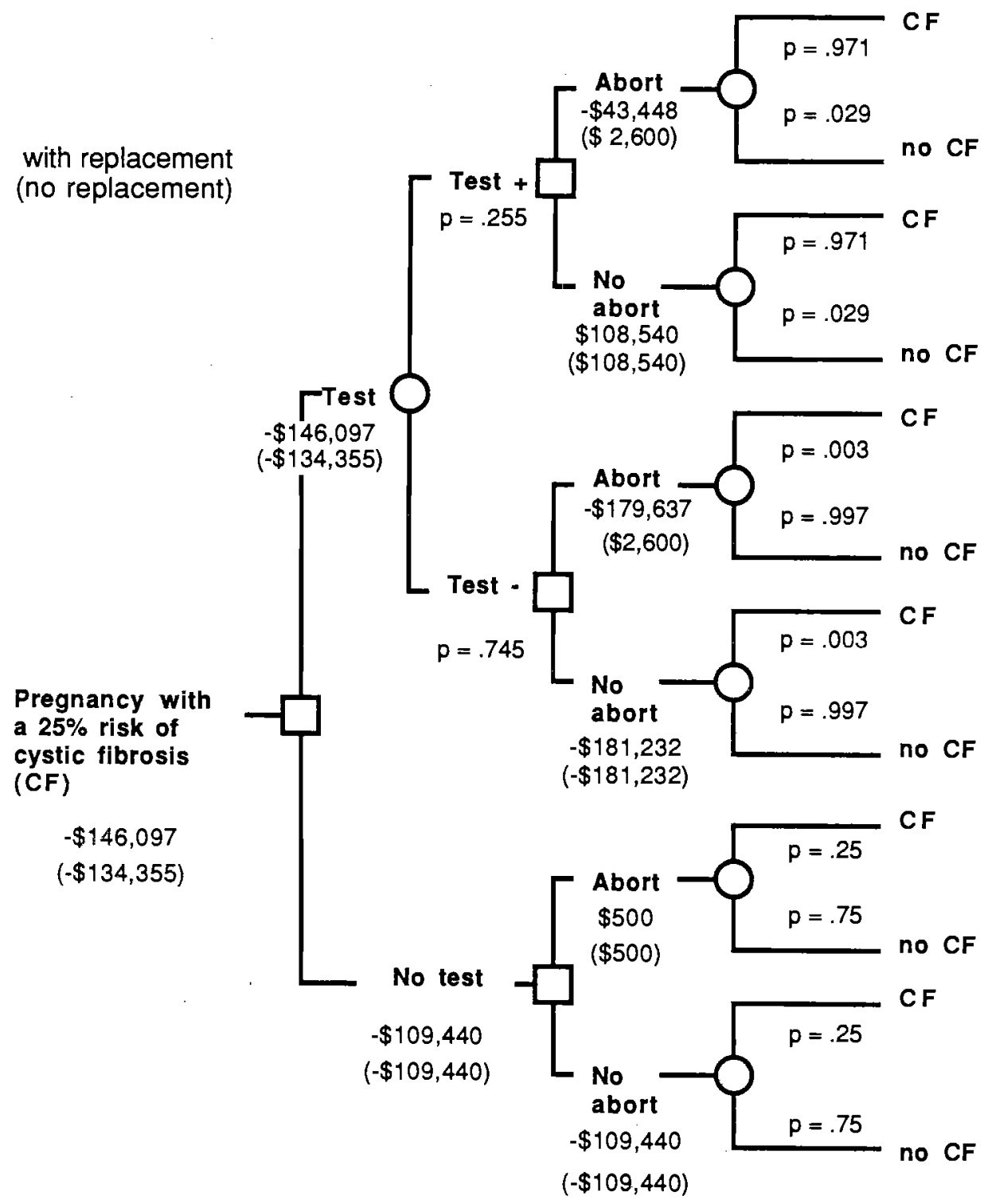

Pregnancy with a $25 \%$ risk of cystic fibrosis (CF)

$-\$ 146,097$

$(-\$ 134,355)$
No test

$-\$ 109,440$

$(-\$ 109,440)$ $(\$ 2,600)$

$\$ 108,540$

$(\$ 108,540)$ $-\$ 179,637$

$(\$ 2,600)$ CF 

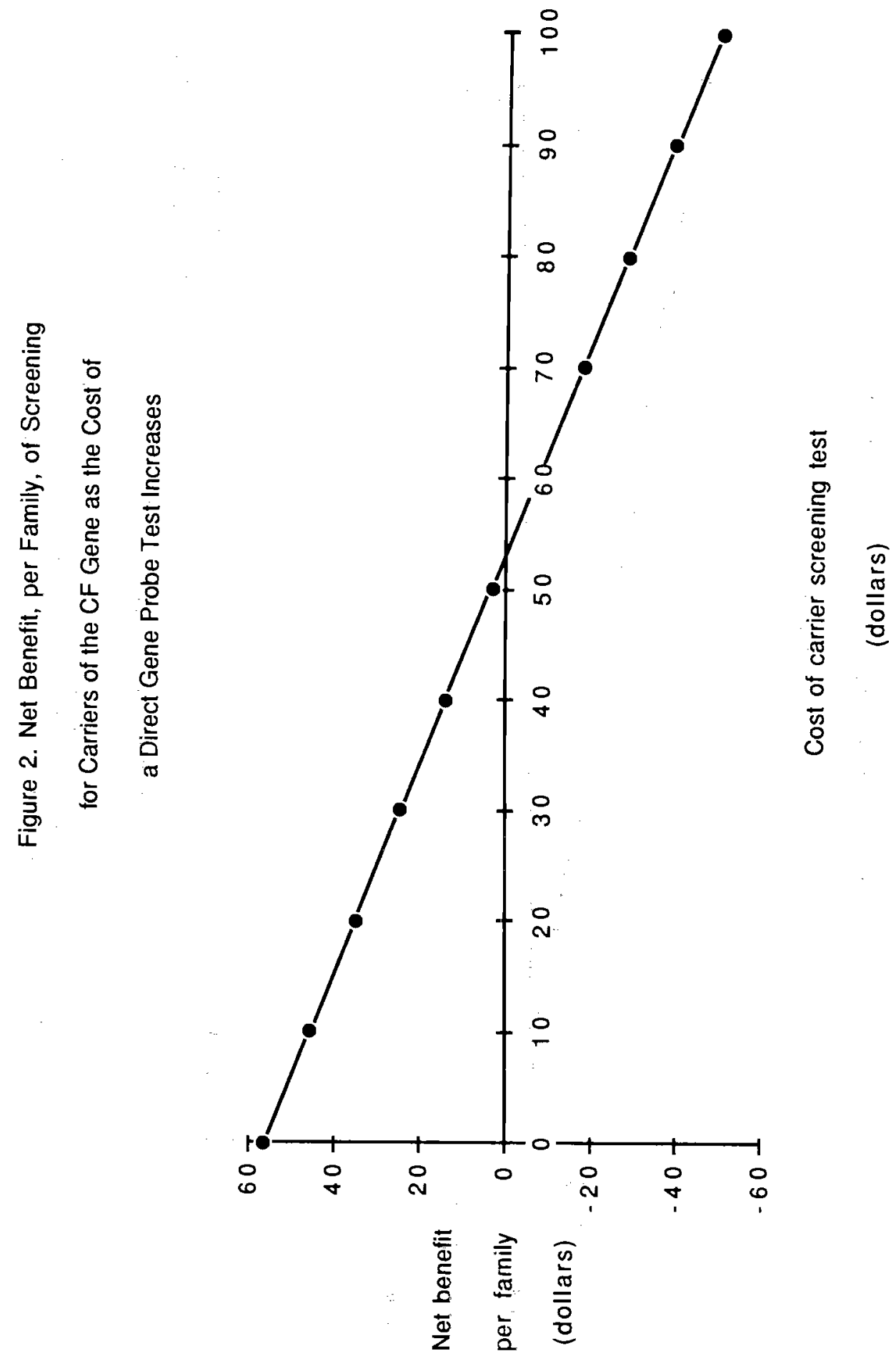

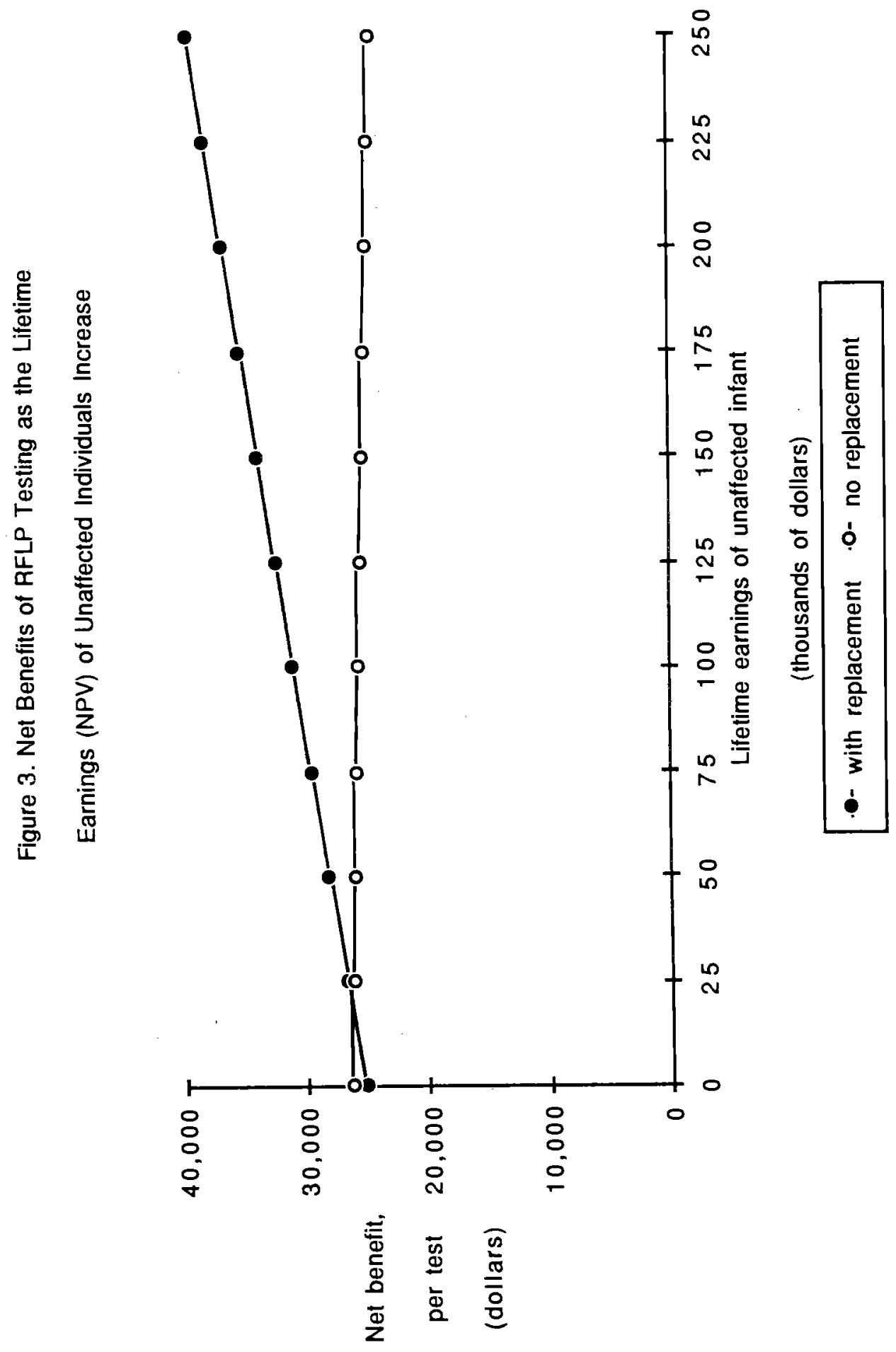


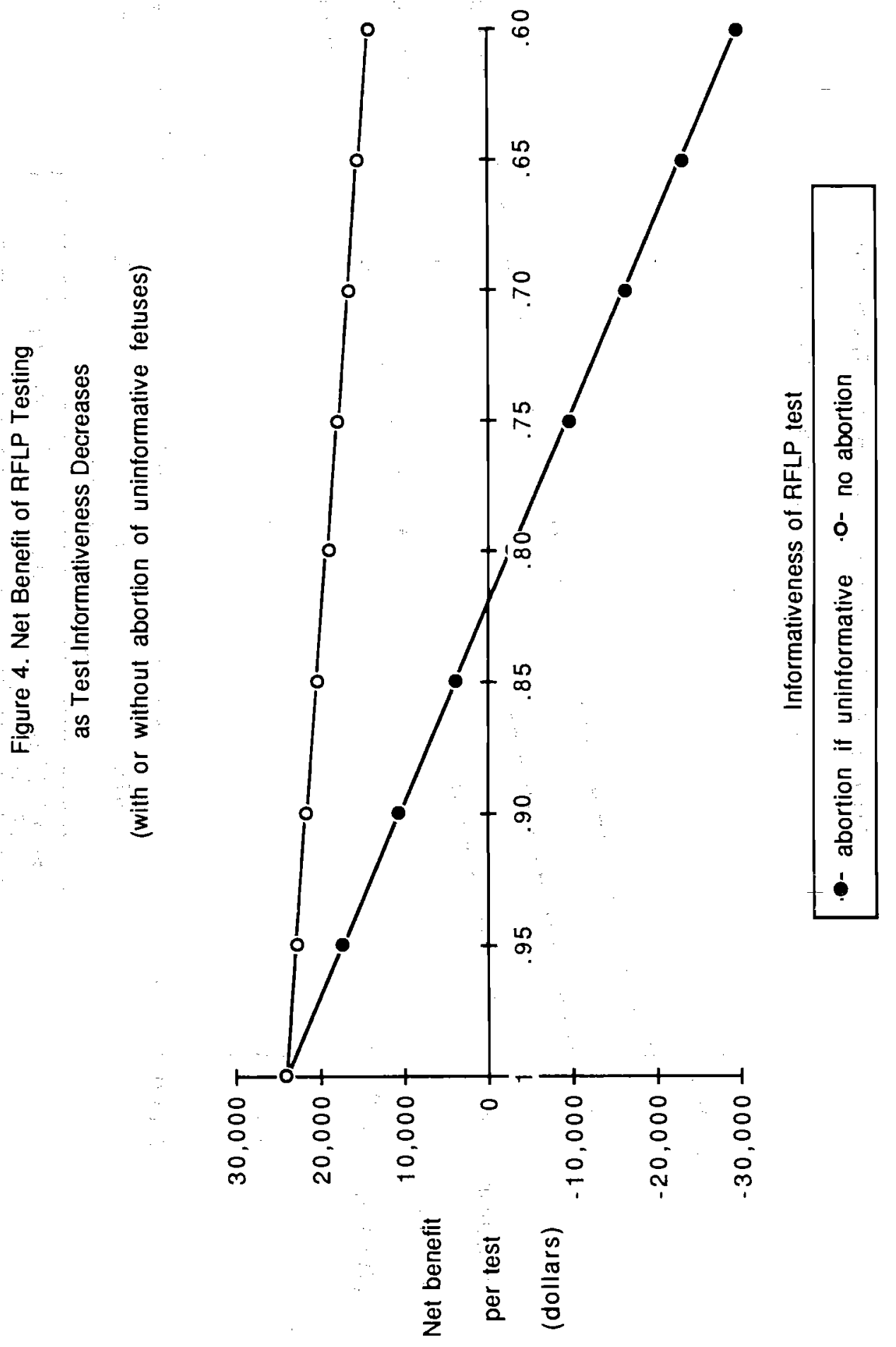




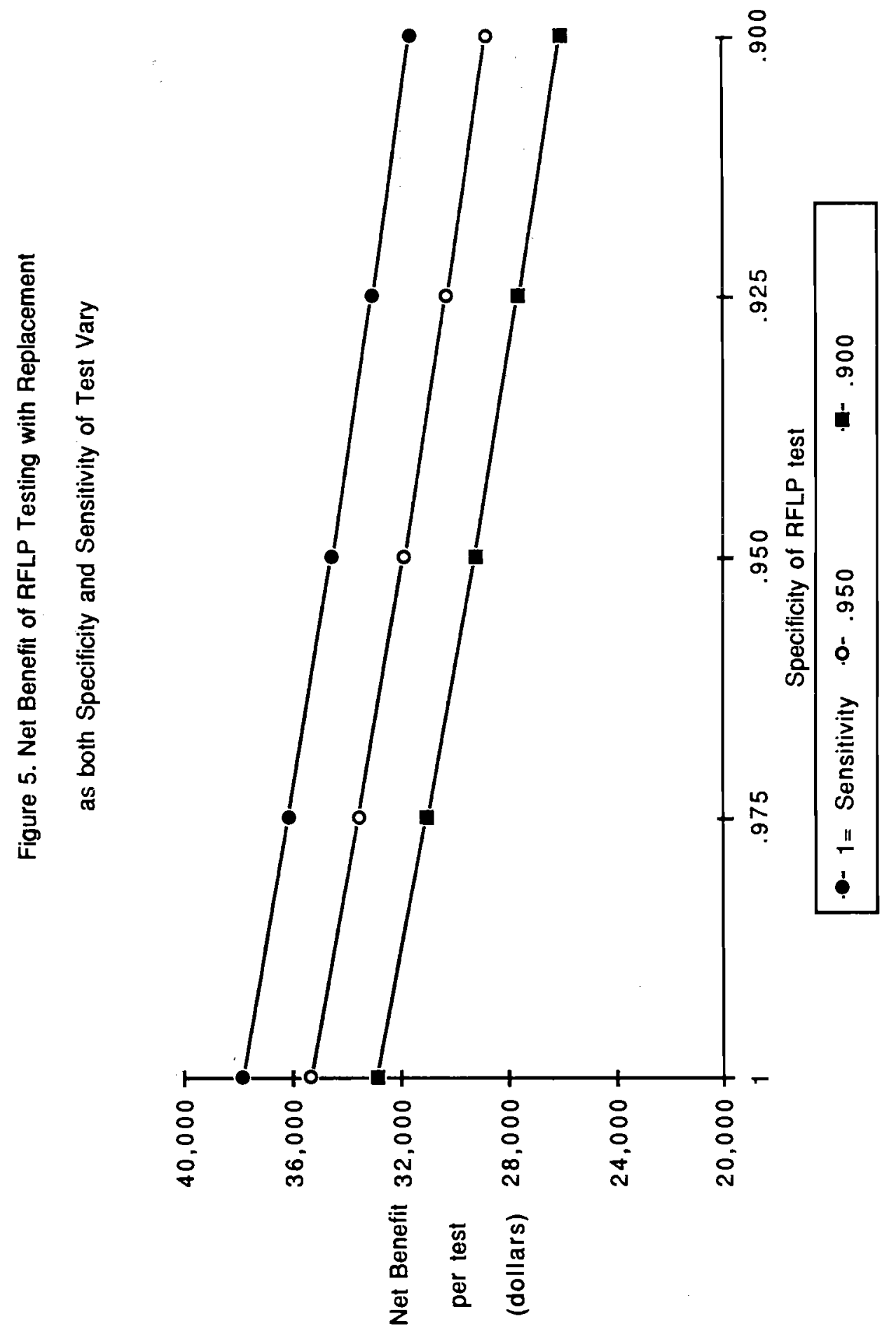




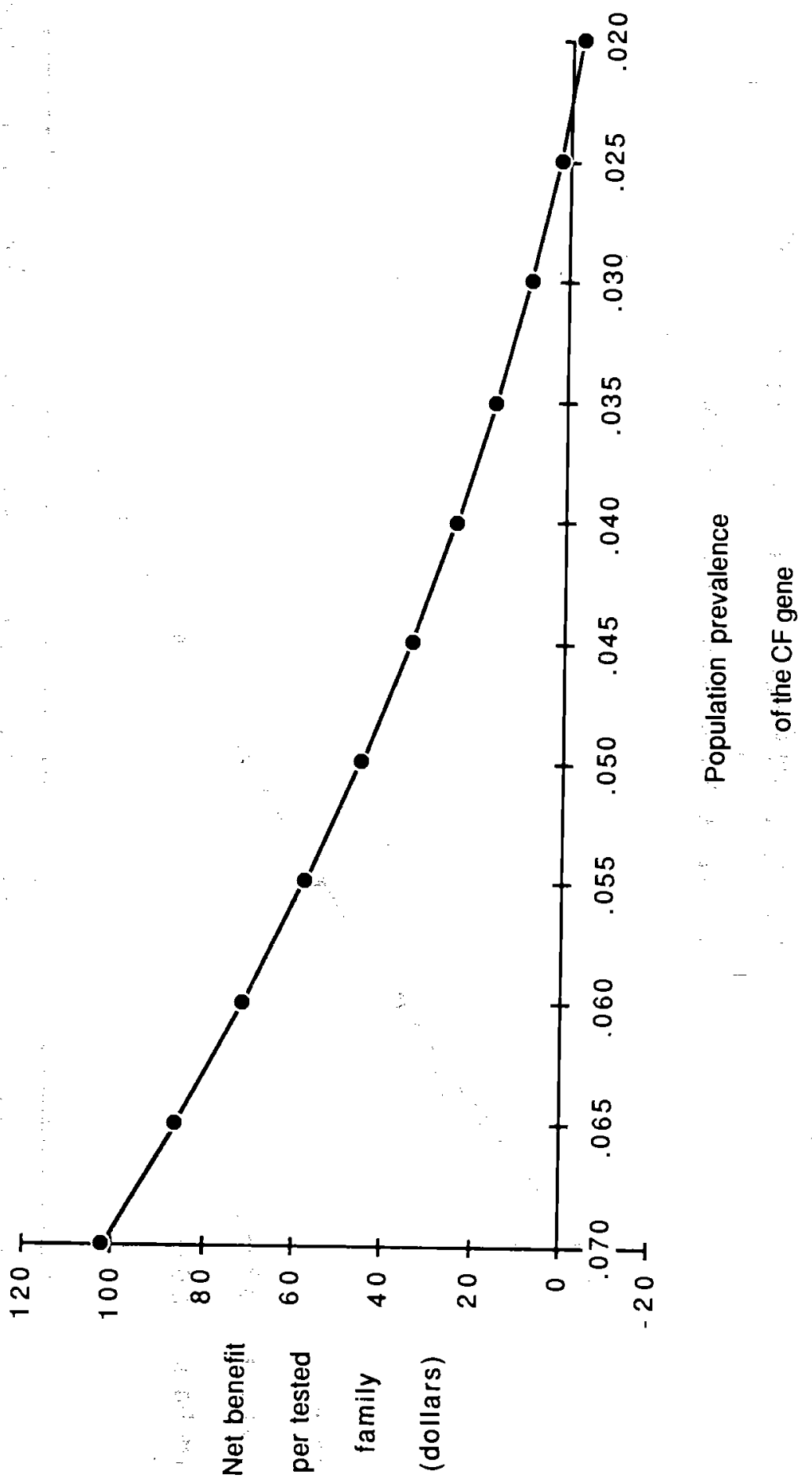




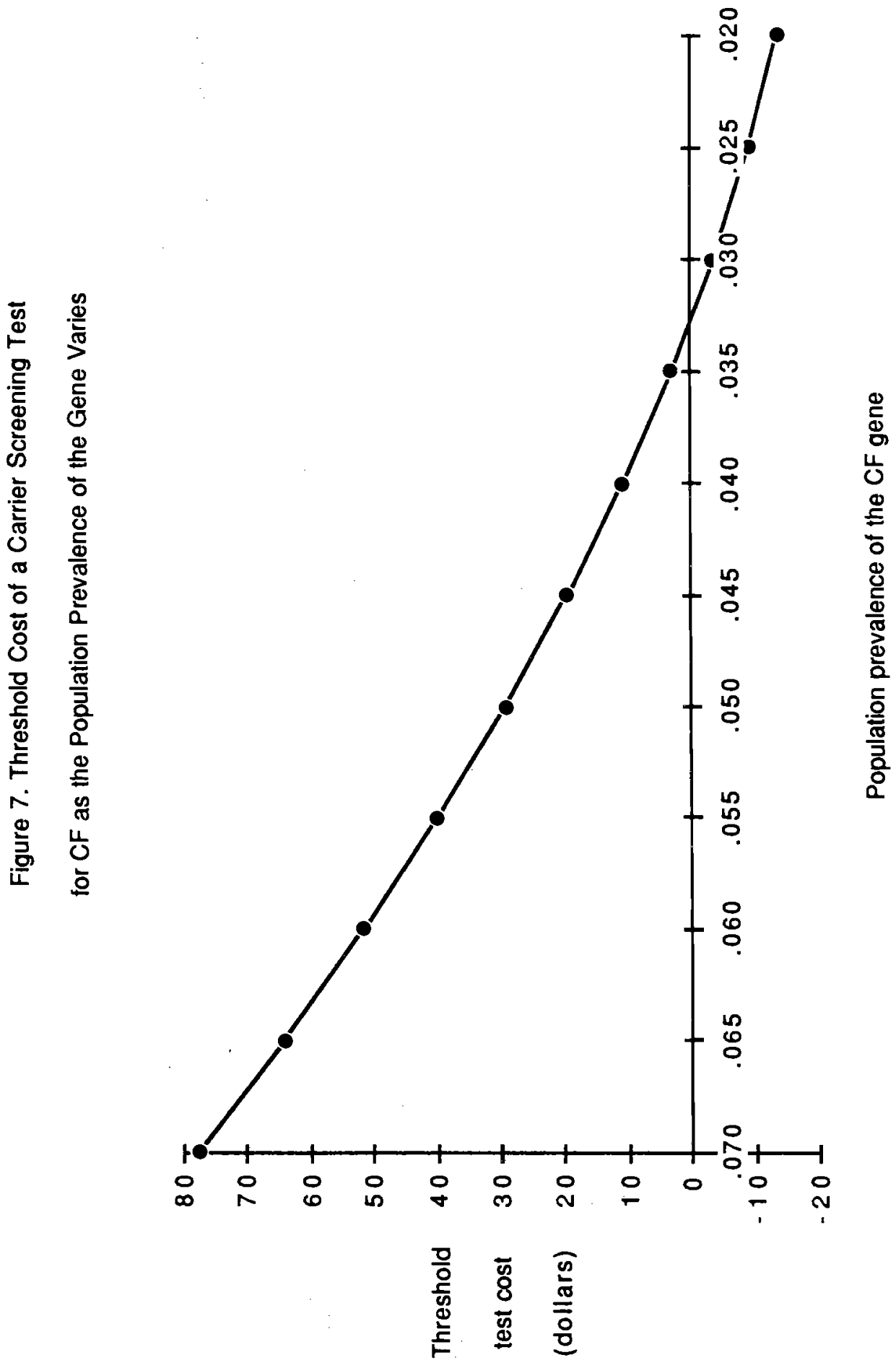



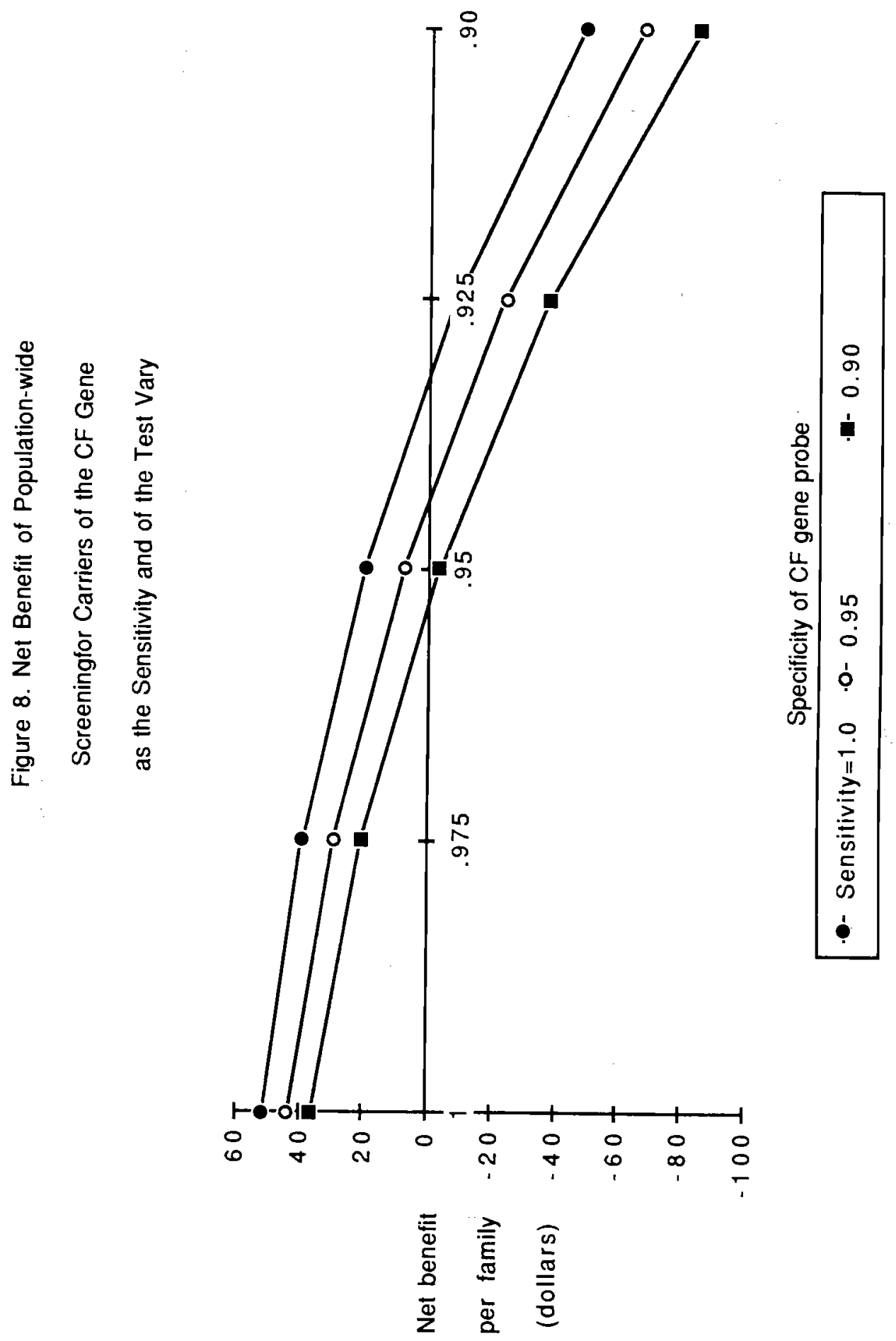
Figure 9. Sequential Testing Strategy for Carrier Screening for the Cystic Fibrosis Gene in the General Population

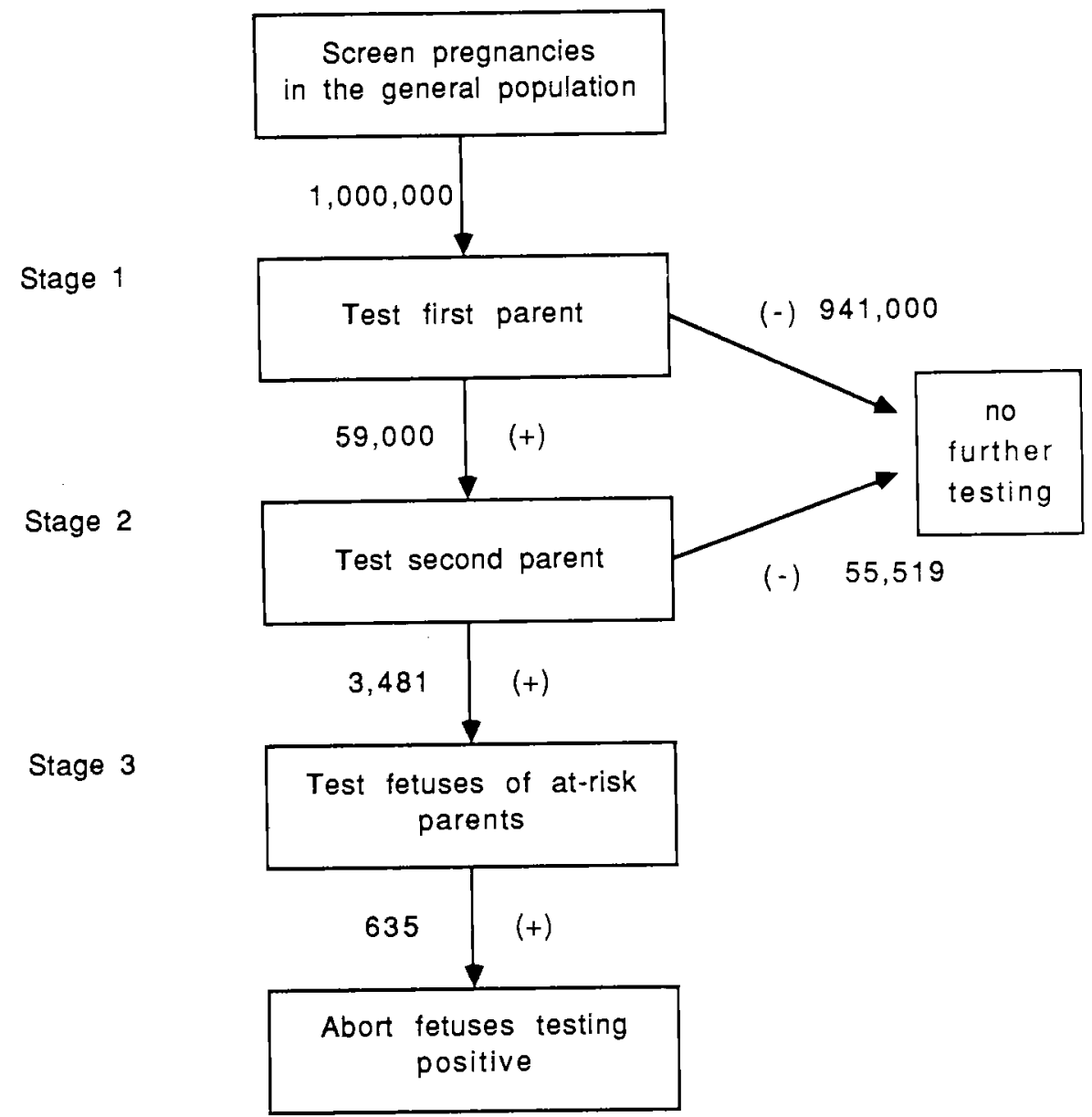

